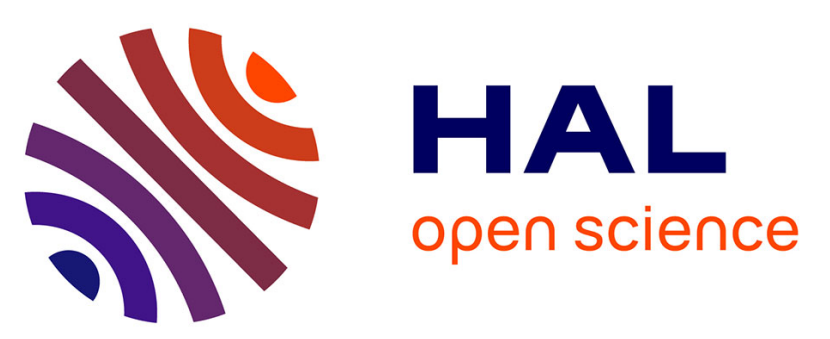

\title{
Density and habitat preferences of male little bustard across contrasting agro-pastoral landscapes in Sardinia (Italy)
}

Andrea Santangeli, Paul M. Dolman

\section{- To cite this version:}

Andrea Santangeli, Paul M. Dolman. Density and habitat preferences of male little bustard across contrasting agro-pastoral landscapes in Sardinia (Italy). European Journal of Wildlife Research, 2011, 57 (4), pp.805-815. 10.1007/s10344-011-0492-3 . hal-00660892

\section{HAL Id: hal-00660892 \\ https://hal.science/hal-00660892}

Submitted on 18 Jan 2012

HAL is a multi-disciplinary open access archive for the deposit and dissemination of scientific research documents, whether they are published or not. The documents may come from teaching and research institutions in France or abroad, or from public or private research centers.
L'archive ouverte pluridisciplinaire HAL, est destinée au dépôt et à la diffusion de documents scientifiques de niveau recherche, publiés ou non, émanant des établissements d'enseignement et de recherche français ou étrangers, des laboratoires publics ou privés. 


\title{
Density and habitat preferences of male little bustard across contrasting agro-pastoral landscapes in Sardinia (Italy)
}

\author{
Andrea Santangeli • Paul M. Dolman
}

Received: 15 May 2010 /Revised: 29 October 2010 /Accepted: 3 January 2011 /Published online: 18 January 2011

(C) Springer-Verlag 2011

\begin{abstract}
The little bustard Tetrax tetrax has undergone severe range contraction within Europe due to abandonment of traditional agro-pastoral activities. Previous studies of habitat selection have mainly focused on extensive cereal and cropland mosaics, while the species' ecology in pastoral landscapes is understood less well, and data are completely lacking from the Sardinian population. We conducted distance sampling surveys of displaying males across three contrasting landscapes in Sardinia and modelled habitat preference at both the landscape and local (within pastures and recent fallows) scale. Abbasanta, with a balance of pasture and cropland, the greatest isolation from roads and shortest vegetation, supported the highest little bustard densities (95\%CI 2.7-3.4 males/100 ha). Significantly lower densities were found in two landscapes with lower isolation from roads and taller vegetation within grasslands: Campeda (0.1-0.2 males/100 ha), comprising cropland and pasture in similar proportions to those found at Abbasanta, and Campidano (0.3-0.4 males/100 ha) that was dominated by cereal agriculture. At the landscape level, males preferred pastures and recent fallows over arable lands. At the local scale, within grasslands, probability of occurrence was greater with shorter vegetation,
\end{abstract}

Communicated by P. Acevedo

A. Santangeli $(\bowtie)$

Finnish Museum of Natural History, University of Helsinki, P.O. Box 17, 00014 Helsinki, Finland

e-mail: andrea.santangeli@helsinki.fi

P. M. Dolman

School of Environmental Sciences, University of East Anglia,

Norwich NR4 7TJ, UK

A. Santangeli

School of Biological Sciences, University of East Anglia, Norwich NR4 7TJ, UK more legume and green herb cover and at points remote from roads. Shorter vegetation in grasslands resulted from high grazing pressure, and habitat suitability for breeding males depends strongly on extensively grazed grasslands. Conservation efforts for this species should focus on maintaining traditional agro-pastoral practices which maintain large areas of extensively grazed pastures and recent fallows located far from roads.

Keywords Semi-natural steppe · Grazing management . Extensive agriculture $\cdot$ Pastoralism .

Agricultural intensification $\cdot$ Tetrax tetrax

\section{Introduction}

Throughout Europe, agricultural landscapes of great antiquity that were created and maintained by traditional farm management practices continue to support important biodiversity wherever they have survived (Tucker 1997; Donald et al. 2001; 2006). In such landscapes, intensification of agricultural practices in mixed-farming areas, coupled with progressive loss of grazed steppe-like grasslands through abandonment of traditional livestock rearing, pose serious threats to biodiversity (Tucker 1997; Chamberlain et al. 2000). Within western Europe, relict-grazed steppe-like grassland landscapes remain in southern France, Spain and parts of Italy (mostly within Sardinia), where pastoralism has a fundamental role in maintaining high conservation value landscapes (Tucker and Evans 1997). The distribution and habitat selection of species of conservation concern may be affected by ecological processes at multiple spatial scales (Vergara and Armesto 2009). It is therefore important to understand the effect of environmental features and land-use effects within agropastoral regions at both landscape and local scales. 
Within Europe, the little bustard Tetrax tetrax is associated with agro-ecosystems comprising low-intensity arable and pastoral areas, particularly mosaics of extensively grazed semi-natural pasture, fallow land and legume crops (Martinez 1994; Wolff et al. 2001). Little bustard is classified as vulnerable in Europe (Tucker and Heath 1994) following severe declines throughout most of its range including its loss from many European countries, attributable to agricultural intensification (Goriup 1994; Del Hoyo et al. 1996). Spain and Portugal support approximately three quarters of the European population; however, within the last 10 years dramatic local declines of up to $75 \%$ have occurred in Spain (García de la Morena et al. 2006; De Juana 2009).

Elsewhere in Europe, three remnant populations occur, with two disjunct populations in France and a third nonmigratory population in Sardinia; while the species is now virtually extinct in mainland Italy (Petretti 2006). The Sardinian population has a long history of geographic isolation, and in contrast to agricultural populations elsewhere (e.g. Jolivet 2001), has been reported to be generally stable over the last two decades (Petretti 2006). In both Sardinia and mainland Italy, little bustard mainly occur in extensively grazed pastures (Petretti 2006). With decreases in traditional livestock grazing, pasture cover in Sardinia was reduced from $64 \%$ in 1960 to less than $10 \%$ in 2000 and from $7.5 \%$ to $2.5 \%$ in coastal mainland Italy during the same period (Falcucci et al. 2007). This was the major cause of loss of little bustard populations in mainland Italy and presents the major threat to the species in Sardinia (De Juana and Martinez 2001; Petretti 2006).

In contrast to the large body of work on little bustards in cropland dominated areas, both in northern France (Salamolard and Moreau 1999) and in Iberia (Martinez 1994; Silva et al. 2007), there has been much less work on the ecology of populations in pastoral-dominated landscapes (but see Wolff et al. 2001), despite their importance for the species (Cramp and Simmons 1980). In Sardinia, although the little bustard is known to occur in both pastoral and agricultural areas, habitat preferences have not been studied. Both landscape-scale landuse and within-field features have been shown to be important for displaying males (Wolff et al. 2001; Traba et al. 2008), but these nested scales have rarely been considered within a single study (but see Martinez 1994) or across contrasting landscapes that differ in composition and disturbance levels.

In this study, we examine habitat preferences of male little bustard in agro-pastoral landscapes at two different spatial scales in order to identify important features to aid conservation management of the species. We consider features at the landscape scale, including the availability of pasture and recently fallowed fields, land-use heterogeneity and human disturbance and at the local scale, including grazing pressure, vegetation structure and composition, and localised human disturbance. We also com- pared density estimates for displaying males among three contrasting landscapes of western Sardinia that differ in land-use composition and structure, recent land-use trends and disturbance levels. From available knowledge of habitat preference of the species, we predicted that males' occurrence would be determined by both large-scale landscape features and small-scale habitat characteristics, with densities higher in the landscape with a balance of pasture and cropland cover and low disturbance levels (Lane et al. 2001; Suarez-Seoane et al. 2002), and predicted lower densities in the more homogeneous landscapes exposed to greater levels of disturbance.

\section{Methods}

\section{Study landscapes}

Three key areas in western Sardinia previously known to support little bustard (Schenk and Aresu 1985) were selected for study (Fig. 1). Each study area lies within, or includes, one of the four Special Protection Areas (SPAs) designated for the species (under EC Directive 79/409/ CEE). To allow land-use extent to be mapped, a contiguous study area was selected at each site, rather than sampling non-contiguous locations or grid cells across the entirety of each landscape. Boundaries of study areas where delimited to cover as much as possible of the large SPAs at Campeda (CA: ITB023050: 19,578 ha of SPA; 59\% of which within the study area) and Abbasanta (AB: ITB023051: 20,103 ha of SPA; $24 \%$ within the study area), while the study area delimited at CO comprised all of the designated SPA (Campidano: ITB043054, 1,564 ha) and a further 12,203 ha of the surrounding Important Bird Area IBA (178-Central Campidano, Fig. 1).

$\mathrm{CA}$ and $\mathrm{AB}$ are upland areas with undulating topography and Meso-Mediterranean sub-humid climate (RivasMartinez 1996) and are dominated by semi-natural steppe, comprising extensive pastures, fallows, arable fields (mainly dry cereals) and hay meadows. Pastures (hereafter indicating grazed land, long-established fallow and natural grasslands), recent fallows and cropped fields are evenly distributed across $\mathrm{AB}$, while at $\mathrm{CA}$ croplands are concentrated in the northwestern river valleys, with the central dry stony plateau dominated by pasture, with scattered hay meadows (Fig. 2). In contrast, the lowland area of $\mathrm{CO}$ has flat topography and a drier Thermo-Mediterranean climate (Rivas-Martinez 1996). It comprises a cereal pseudosteppe landscape (sensu Suarez et al. 1997), dominated by cereal fields, interspersed with irrigated crops such as lucerne, and occasional pastures (Fig. 2).

Landscape composition data from 2000 (Table 2) were extracted from regional land-use maps based on CORINE 
Fig. 1 Location of the three study areas (dark grey areas) in central-western Sardinia, with location map relative to Italy. Thick black lines show boundaries of Special Protection Areas ( $C A$ Campeda ITB023050, $A B$ Abbasanta ITB023051, CO Campidano ITB043054), thin black lines show the boundaries of Important Bird Areas (IBA177: Campeda Highlands; IBA179: Abbasanta Highlands and Omodeo Lake; IBA178: Central Campidano)

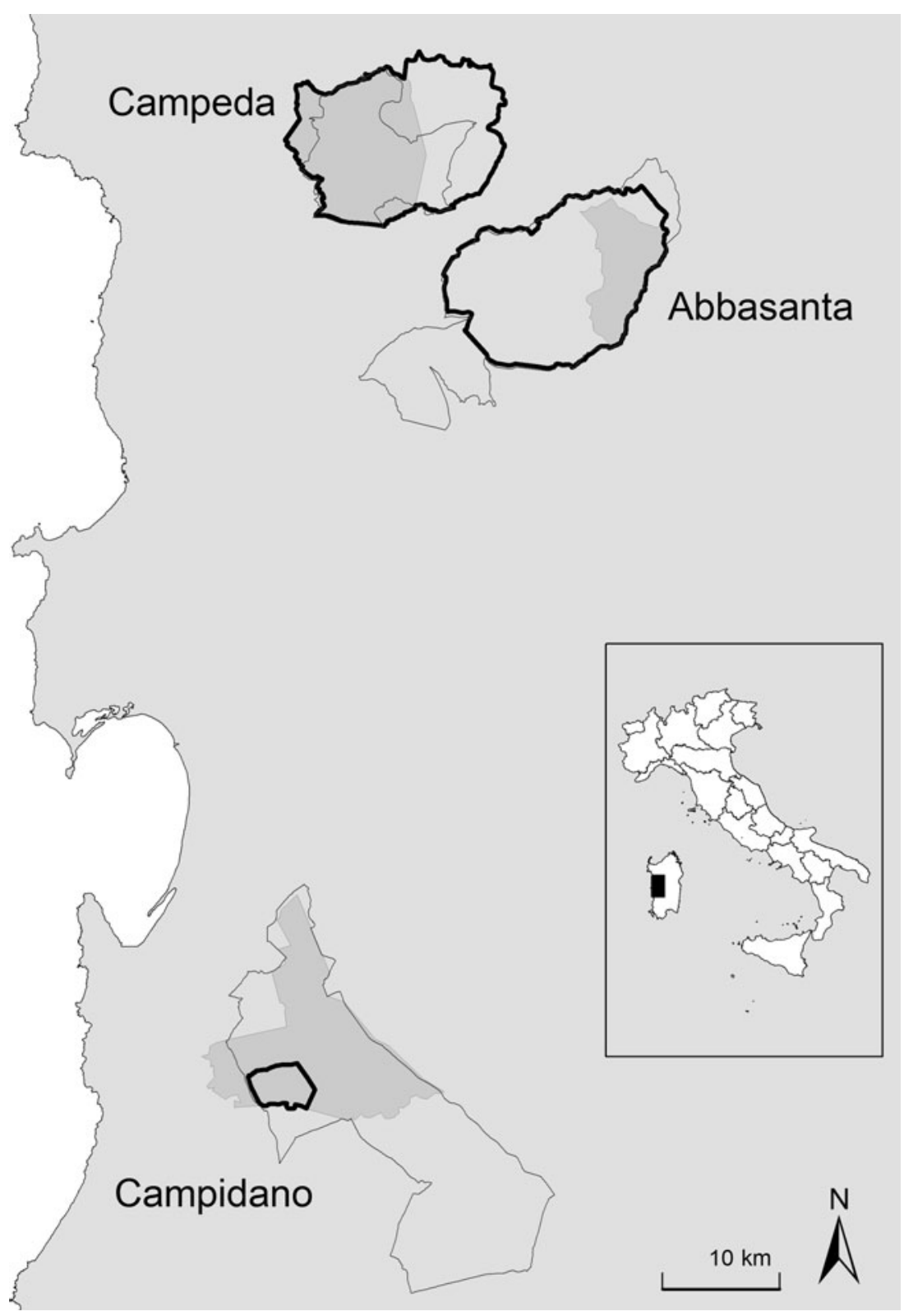

Land Cover classes (scale 1:25,000), considering pasture (all natural grasslands and long-established fallows), cropland (including cereal and other crops, recent fallows and hay meadows) and pooling unsuitable land-cover types (villages, infrastructures, vineyards and woodlands). Landuse data from 2000 were updated during fieldwork in 2008, with the aid of hand-held GPS, to quantify changes in these three broad land-cover categories (pasture, cropland, unsuitable) and to quantify the frequency of specific cropland types (recent fallow, hay meadow, wheat/barley, oat and legume crops) within the three study areas. Recent fallows were identified during fieldwork in 2008 by the presence of therophytic and absence of perennial geophytic plants (mainly of the genus Ferula and Asphodelus).
Survey of male density

Male little bustard display activity is concentrated between April and June in Sardinia (Petretti 1993). Surveys were conducted from 1 May to 8 June 2008, between 0600 to 0900 hours and 1800 to 2100 hours (GMT+1:00), when male display activity is greatest (De Juana and Martinez 1996), except during rain or strong wind which reduces display activity and detection (Wolff et al. 2001).

To allow maximal areal coverage, a combination of point counts and distance transects were used. At $\mathrm{CO}$, a network of secondary roads and tracks covering all the landscape allowed the surveyor to drive between sampling locations; consequently at this site only point transects were 


\section{Campidano}

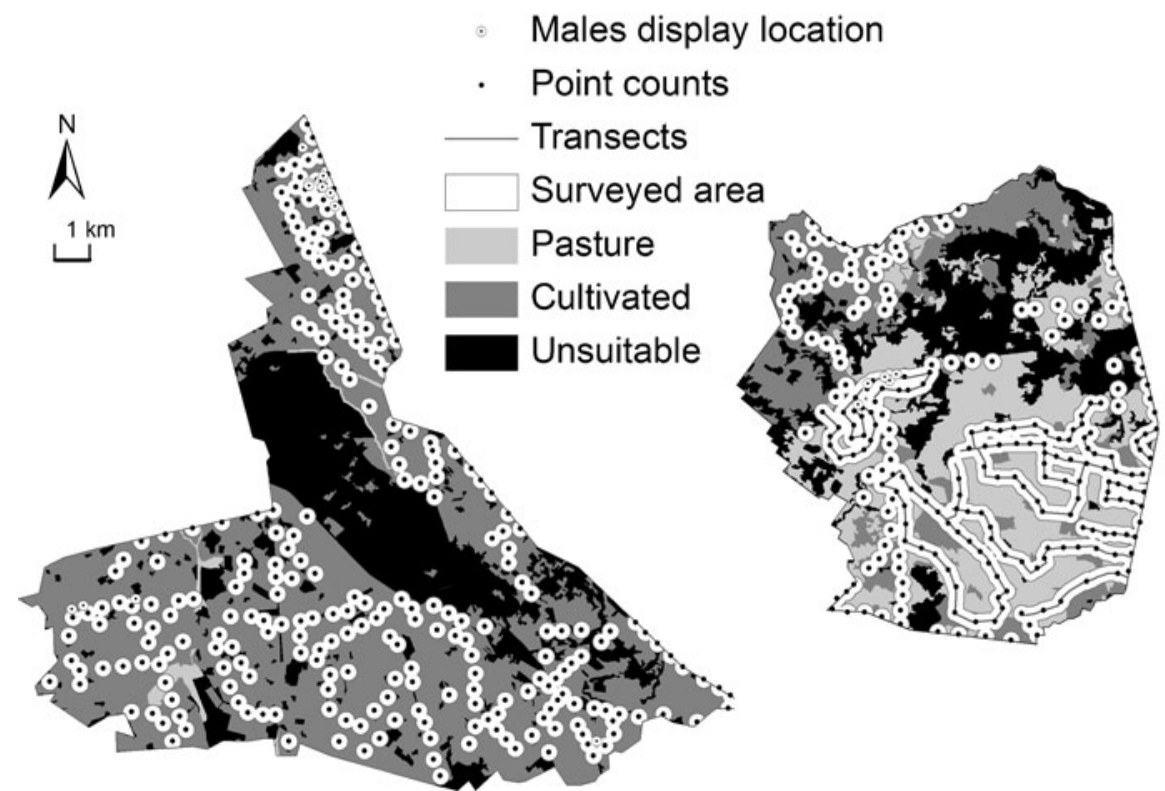

Abbasanta
Campeda

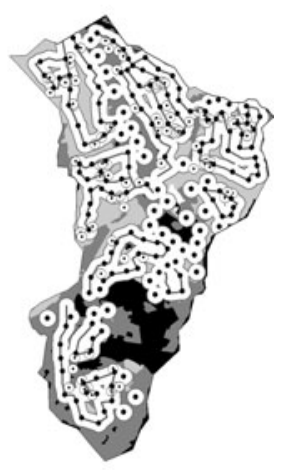

Fig. 2 Location of displaying male observations, transects and point counts across suitable habitat within each of the three study sites. The surveyed areas shown as buffers around transects and point counts represent the mean effective detection radius and effective strip widths estimated in distance and used for density calculations

composite area covered by each survey calculated. This was repeated for upper and lower 95\%CI values of EDR and ESW. Density and population estimates (mean and 95\%CI) for each study area were calculated on the basis of males detected, areas surveyed and extent of available habitat cover.

\section{Habitat sampling}

Habitat was sampled at 96 locations with displaying male little bustard, and at 120 control (absence) points, randomly located across each site while excluding unsuitable land-cover types for the species (woodland, vineyard or infrastructure). Control points were located further than $150 \mathrm{~m}$ from the nearest territory, considering mean male territory area of 6.7 ha in France (Jiguet et al. 2000). At each point, 15 variables were measured (Table 1), seven of those related to landscape scale and eight to small-scale (within-grassland) habitat characteristics. The landscape variables recorded included: land-use type, land-use heterogeneity and number of bushes and trees within $150 \mathrm{~m}$ from the point centre. Land-use heterogeneity, consisting of the counted number of the five different landuse categories, was again recorded within $150 \mathrm{~m}$ from the point centre based on known male territory area of 6.7 ha (approximately $150 \mathrm{~m}$ radius; Jiguet et al. 2000). Points with high heterogeneity were scarce and were pooled into a single class with value greater than two for computational purposes (Table 1). In addition, in view of the known sensitivity of bustards to human disturbance and infrastructure (Lane et al. 
Table 1 Landscape elements (bold font) and local scale (within semi-natural grassland and recent fallows) habitat variables recorded at the 216 survey points across three study areas within Sardinia

\begin{tabular}{|c|c|c|}
\hline Variable & Source of data & Description of the variable \\
\hline Land-use & Field data & \\
\hline Pasture & & Natural pastures and long fallow land (left set aside for more than 1 year) \\
\hline Recent fallow & & Land left set aside for 1 year \\
\hline Arable & & All cultivated land which is not irrigated \\
\hline Hay meadow & & Unploughed cropland \\
\hline Other & & Ploughed land, xerophilic steppe ( $>60 \%$ bare or stony ground), irrigated land \\
\hline Land-use heterogeneity & Field data & $\begin{array}{l}\text { The number of land-use categories counted within } 150 \mathrm{~m} \text { of the point (classes: low=1, } \\
\text { med }=2 \text { and high }=3 \text { to } 5 \text { ) }\end{array}$ \\
\hline Distance to roads & Military maps & Distance to the nearest asphalted road \\
\hline Distance to tracks & Military maps & Distance to the nearest dirt track \\
\hline Distance to buildings & Military maps & Distance to the nearest actively used building \\
\hline Distance to wires & Military maps & Distance to the nearest aerial power line \\
\hline Bushes/trees & Field data & The number of woody plants (height $>2 \mathrm{~m}$ ) present within $150 \mathrm{~m}$ of the point \\
\hline Vegetation height & Field data & Measured using a sward stick to the nearest $\mathrm{cm}$ \\
\hline Grazing pressure & Field data & $\begin{array}{l}\text { Range } 0-8 \text {, calculated as the number of eight transects (each } 2 \times 10 \mathrm{~m} \text { ) searched for sheep } \\
\text { faecal pellet groups. }\end{array}$ \\
\hline Bare/rocky soil cover & Field data & Estimated $\%$ of surface with no vegetation cover \\
\hline Oat cover & Field data & Estimated $\%$ of surface covered by oat \\
\hline Wheat/barley cover & Field data & Estimated $\%$ of surface covered by wheat or barley \\
\hline Legume cover & Field data & Estimated $\%$ of surface covered by leguminosae plants (e.g. Trifolium and Medicago spp.) \\
\hline Green herbs cover & Field data & $\begin{array}{l}\text { Estimated \% of surface covered by green non-leguminosae herbs (particularly Cruciferae } \\
\text { and Compositae) }\end{array}$ \\
\hline Other vegetation cover & Field data & $\begin{array}{l}\text { Estimated \% of surface covered by dry grass or other vegetation (mainly Poa and } \\
\text { Cardus spp.) not included in the previous classes }\end{array}$ \\
\hline
\end{tabular}

2001; Suarez-Seoane et al. 2002), we also considered four proxies of disturbance (distance to roads, tracks, buildings and wires) measured from 1:25,000 military maps derived from 1999 and updated in the field in 2008 (Table 1).

Small-scale habitat variables included percentage cover of each of six vegetation classes estimated within nine quadrats (of $1 \mathrm{~m} \times 1 \mathrm{~m}$ ), with one located at the centre and others at 10 and $20 \mathrm{~m}$ along the four cardinal directions (following Silva et al. 2007; Table 1). Vegetation height was also recorded by taking 20 measures using a sward stick $(15 \mathrm{~cm}$ radius and $70 \mathrm{~g}$ weight) randomly placed within $20 \mathrm{~m}$ radius of the point centre. We also recorded whether sheep faecal pellets were present in each of eight strip transects (of $2 \mathrm{~m} \times 10 \mathrm{~m}$ ) along the four cardinal directions from the point centre. An index of grazing pressure was considered ranging from zero (no pellets recorded) to eight (pellets present on each strip transect) following Silva et al. (2007). All data were collected by the same observer (AS).

\section{Data analysis}

Displaying male habitat preference was analysed by constructing two multivariate logistic regression models with bustard presence or absence as the response. The first model, including all 216 sample points, considered the seven landscape-scale variables (Table 1): land-use, landuse heterogeneity (the number of the five different landuses counted within $150 \mathrm{~m}$ from the sample point; categories - low $=1$, medium $=2$ and high $=\geq 3$ ), number of bushes and trees, and the four measures of human disturbance (distance to roads, tracks, buildings and wires). The second model considered only the 155 sample (presence and absence) points located within pasture and recent fallows and included the four measures of human disturbance (distance to infrastructures in Table 1) in addition to the seven small-scale variables of habitat structure and quality: vegetation height and the percentage cover of bare or rocky soil, oat, wheat or barley, legumes, herbs and other vegetation material. Wheat and barley were pooled into a single cover category as both were scarce and have similar structure and phenology in our study landscapes.

Land-use and land-use heterogeneity were entered in the first model as categorical predictors, and study area was controlled for in both models as a categorical fixed effect. Inter-correlation among candidate variables was examined using Pearson's correlation. It is appropriate to simultaneously include inter-correlated predictors within a multivariate model, provided the correlation coefficient is less 
than approximately $0.7-0.8$ (Freckleton 2002). All pairwise correlations among our variables were below 0.6 , with the exception of vegetation height which was strongly correlated with grazing pressure $(r=-0.71$; pooling sample points within pastures and recent fallows). We therefore excluded grazing pressure from the second model based on its lower contribution to the model (judged by -2 loglikelihood ratio, LLR) compared to vegetation height.

Whether the distance to infrastructures (roads, tracks, buildings and wires) differed among the five land-use types and between the three study areas was analysed by means of analysis of variance (ANOVA) using random points only and including an interaction term for land-use type with study area. None of the four distance variables differed significantly among land-use types.

Full initial logistic models including all candidate variables were simplified by backward elimination, removing one variable at a time and assessing the change in Log-Likelihood Ratio ( $-2 \mathrm{LLR}$, with $P \geq 0.05$ ). Model goodness-of-fit was assessed by classification accuracy, with a probability threshold of 0.5 (Hosmer and Lemeshow 2000) and by calculating the area under the receiver operating characteristics curve (AUC) with associated standard error. Spatial autocorrelation of model residuals were examined by Moran's I test and visual investigation of spline correlogram (plotting correlation coefficients with $95 \%$ pairwise bootstrap confidence intervals as a function of distance). As residuals of the landscape-scale model were spatially autocorrelated, we also built a spatial generalised linear mixed model (using the proc glimmix procedure in SAS) following Dormann et al. (2007). Within pastures and recent fallows, vegetation height (square root transformed to fit normality) was related to grazing pressure considering all random and presence points in a general linear model, with grazing pressure as covariate, study area and land-use (classes: pasture and recent fallow) as categorical fixed factors. The interactions between grazing pressure and study area, and study area with land-use were tested in the model and removed if non-significant. The two logistic models were built using SAS version 9.2 (SAS Institute, Cary, NC, USA). PASW Statistics 18 (PASW Statistics 18 Inc. 2010) was used for all other tests.

\section{Results}

Landscape- and local- scale habitat characteristics

Both the current extent of land-cover classes, and their recent history, differed markedly among the three study areas. $\mathrm{CO}$ was dominated by cropland, while pasture was extremely scarce, both in the 2008 field survey and in the
Table 2 Total areas and percentage extent of pasture, cropland (including legume crops, recent fallows, hay fields and dry cereal fields) and habitat unsuitable for little bustard in vegetation maps from 2000 (extracted from CLC2000 dataset) and 2008 (updated in the field; also shown in Fig. 2) in each of three study areas within Sardinia

\begin{tabular}{|c|c|c|c|c|c|c|}
\hline \multirow[b]{2}{*}{ Year } & \multicolumn{2}{|l|}{$\mathrm{AB}$} & \multicolumn{2}{|l|}{$\mathrm{CA}$} & \multicolumn{2}{|l|}{$\mathrm{CO}$} \\
\hline & 2000 & 2008 & 2000 & 2008 & 2000 & 2008 \\
\hline Total area (ha) & 4,912 & & 11,555 & & 15,305 & \\
\hline \multicolumn{7}{|c|}{ Land-use (\% area): } \\
\hline Unsuitable & 20.2 & 12.2 & 24.2 & 24.6 & 14.8 & 26.3 \\
\hline Pasture & 3.6 & 44.4 & 43 & 45.4 & 1.4 & 1.1 \\
\hline Cropland & 76.2 & 43.4 & 32.8 & 30 & 83.8 & 72.6 \\
\hline \multicolumn{7}{|c|}{ Crop type (\% cropland): } \\
\hline Lucerne & & 10 & & 9.1 & & 13.0 \\
\hline Oat & & 2.5 & & 9.1 & & 8.7 \\
\hline Barley/wheat & & 7.5 & & 18.2 & & 30.4 \\
\hline New fallow & & 42.5 & & 9.1 & & 26.1 \\
\hline Hay meadow & & 30 & & 45.5 & & 17.4 \\
\hline Other & & 7.5 & & 9.1 & & 4.4 \\
\hline
\end{tabular}

The percentage of each crop type within the cropland land-use is shown from field data collected in 2008 only

earlier 2000 land-cover maps (Table 2). Despite the continued dominance of cropland at $\mathrm{CO}$, its extent had slightly reduced through conversion to unsuitable land-uses for the little bustard (mostly vineyards). During field survey in $2008,26 \%$ of the cropland sampled at random points within CO comprised recent fallows. In contrast, in 2008 landscapes at both $\mathrm{CA}$ and $\mathrm{AB}$ had approximately half the cover of cropland than at $\mathrm{CO}$, and a much greater extent of pasture than at $\mathrm{CO}$, with pasture having similar extent to croplands (Table 2). However, they differed in recent history. Land-cover extent had been stable at CA between 2000 and 2008. In contrast, at AB cropland extent had reduced greatly; from approximately three quarters in 2000 to $43 \%$ of the landscape in 2008 , with a corresponding expansion of pasture that had been almost absent in 2000 (Table 2). Additional recent fallows were common at $\mathrm{AB}$, comprising $43 \%$ of random points within cropland, compared to $9 \%$ at CA.

Random points at $\mathrm{AB}$ were significantly further from roads (mean \pm SE $697 \pm 63 \mathrm{~m}$ ) than those at $\mathrm{CA}$ and $\mathrm{CO}$ $(474 \pm 119 \mathrm{~m}$ and $332 \pm 64 \mathrm{~m}$ respectively; site effect in ANOVA controlling for land-use and land-use interaction: $F_{2,119}=6.105, P=0.003$, Tukey tests $P<0.05$ ). Random points in $\mathrm{AB}$ were also more distant from tracks $(239 \pm$ $26 \mathrm{~m})$ than in $\mathrm{CO}\left(109 \pm 17 \mathrm{~m} ; F_{2}, 119=3.521, P=0.033\right.$, Tukey test $P<0.05$ ), but distance to tracks was similar between random points in $\mathrm{AB}$ and $\mathrm{CA}(161 \pm 29 \mathrm{~m}$ in CA; Tukey test $P=0.248)$. Distance of random points to wires and buildings was similar among the three study areas $(P=$ 
0.388 and 0.254 , respectively) when controlling for the effect of land-use type.

Considering pastures and recent fallows, vegetation height was negatively related to grazing pressure (GLM controlling for site and pasture versus fallow: $r^{2}=0.56$; grazing: $\left.F_{1,154}=124.63, P<0.001\right)$ and differed significantly among study areas (fixed effect: $F_{2,154}=5.57, P=0.005$ ), with pastures and recent fallows at $\mathrm{AB}$ having shorter vegetation (mean $=22.2 \mathrm{~cm} \pm 1.1 \mathrm{SE}$ ) than those in $\mathrm{CO}$ (mean $=33.4 \mathrm{~cm} \pm 4.3 \mathrm{SE}, P=0.013$ ) and $\mathrm{CA}$ (mean= $28.3 \mathrm{~cm} \pm 4.0 \mathrm{SE}, P=0.034)$. Vegetation was also shorter in pasture (mean $21.1 \mathrm{~cm} \pm 1.2 \mathrm{SE}$ ) than in recent fallows (32.4 $\mathrm{cm} \pm 2.2$, respectively; $F_{1,154}=4.497, P=0.036$ ). Nonsignificant interactions between grazing pressure and study area and study area versus land-use type were excluded from the reduced model.

Comparison of male little bustard density among contrasting landscapes

The 31 transects and 675 point counts provided 112 observations (45 and 67 for each method, respectively) of displaying male little bustard across the three sites. For distance transects, the half-normal detection function was best supported ( $\mathrm{ESW}=226.5 \mathrm{~m} \pm 11.4 \mathrm{SE}, \mathrm{AICc}=528.80$ ) and was used for density estimation; a hazard-rate model performed almost as well $(\triangle \mathrm{AICc}=0.3)$ and provided a very similar though less precise ESW (234.2 $\mathrm{m} \pm 35.2 \mathrm{SE})$. For point counts, the uniform function with cosine adjustment was supported $(\mathrm{EDR}=246.9 \pm 12.2 \mathrm{SE}, \mathrm{AIC}=718.4)$, the next best function (half-normal) had considerably larger AIC $(\triangle \mathrm{AIC}=2.4)$.

A large population was detected in $\mathrm{AB}$, with densities 23 and 10 times higher than $\mathrm{CA}$ and $\mathrm{CO}$, respectively (Table 3); the lack of overlap of $95 \% \mathrm{CI}$ indicates that density differed significantly among the three sites.
Male little bustard habitat preference

\section{Landscape scale}

The multivariate logistic model built pooling data from across the three areas showed moderate internal model fit (AUC $=0.79 \pm 0.03 \mathrm{SE}$ ) and spatially autocorrelated residuals (Moran's $I$ test, $P<0.05$ ) with positive correlation between points occurring within a distance of approximately $1,000 \mathrm{~m}$. A spatial model that explicitly incorporates spatial correlation had a marginally lower model fit (AUC $=0.73 \pm 0.03 \mathrm{SE})$. The spatial model retained only the land-use variable as significant (Table 4a), with preference for pasture and new fallows (Fig. 3a). The non-spatial model included effects of both land-use and land-use heterogeneity (Table 4b). This model predicts male little bustards to occur significantly more often in pasture and recent fallows (Fig. 3b; amounting 70 and 17 male detections, respectively) than in either arable (only one male detected), hay meadow or other land-use classes (two and six detections, respectively). Males' occurrence in the non-spatial model was also significantly lower at points with either low or medium land-use heterogeneity, compared to points with high land-use heterogeneity within $150 \mathrm{~m}$ (Fig. 3c).

Disturbance variables (distance to buildings, tracks, roads or wires) were not retained in either the spatial or non-spatial model (Table $4 \mathrm{a}$ and $4 \mathrm{~b}$ ), indicating that they contributed little to explaining incidence of males' presence at this scale.

\section{Local scale, within pastures and recent fallows}

The multivariate model considering small-scale habitat elements and wider-scale disturbance variables within pasture and recent fallows (Table 4c) had high classification

Table 3 Extent of study areas, suitable habitat available and the area covered by combined distance transect and point surveys are given. Numbers of calling birds detected and estimates of the density and total numbers of males within each of three study areas within Sardinia are also presented

\begin{tabular}{llll}
\hline & AB & CA & CO \\
\hline Total study area (ha) & 4,912 & 11,555 & 15,305 \\
Suitable habitat available (ha) & 4,314 & 8,712 & 11,281 \\
Suitable habitat surveyed by distance sampling (ha) & $3,145(2,818-3,489 ; 73 \%)$ & $3,891(3,395-4,457 ; 45 \%)$ & $3,916(3,346-4,531 ; 35 \%)$ \\
Number of males detected & 95 & 5 & 12 \\
Density (males per 100 ha) & $3.02(2.72-3.37)$ & $0.13(0.11-0.15)$ & $0.31(0.26-0.36)$ \\
Population estimate within study areas (based on & $130(117-145)$ & $11(10-13)$ & $35(30-40)$ \\
$\quad$ available habitat present) & 20,103 & 19,578 & 1,564 \\
Area of the SPA (ha) & $24 \%$ & $59 \%$ & $100 \%$
\end{tabular}

CI $(95 \%)$ of surveyed area (with \% of suitable habitat covered by survey), density and population estimates are given within brackets. Extent of SPAs and the $\%$ of SPA covered by the study area are also shown 
Table 4 Minimal multivariate logistic regression results. Results show (a) landscape-scale spatial model and (b) landscape-scale non-spatial model of male preference (considering points across all land-use types: $n=96$ presences, 120 absences), and (c) local scale preference, within pastures and recent fallows (including habitat structure and disturbance variables: $n=87$ presences, 68 absences)

\begin{tabular}{|c|c|c|c|c|c|c|c|c|}
\hline Variables & $B$ & SE & $-2 \mathrm{LLR}$ & $P$ & $\chi^{2}$ & $d f$ & $P$ & $\mathrm{AUC} \pm \mathrm{SE}$ \\
\hline (a) All land-use types (spatial model) & & & & & & & & $0.73 \pm 0.03$ \\
\hline Land-use (presence) & & & 6.19 & $<0.001$ & & & & \\
\hline Site & & & 2.42 & 0.091 & & & & \\
\hline Constant & -2.033 & 0.639 & & & & & & \\
\hline (b) All land-use types (non-spatial model) & & & & & 64.7 & 8 & $<0.001$ & $0.79 \pm 0.03$ \\
\hline Land-use (presence) & & & 22.492 & $<0.001$ & & & & \\
\hline Land-use heterogeneity & & & 10.725 & 0.005 & & & & \\
\hline Site & & & 9.978 & 0.007 & & & & \\
\hline Constant & -0.330 & 0.729 & & & & & & \\
\hline (c) Pasture and recent fallow & & & & & 116.0 & 6 & $<0.001$ & $0.94 \pm 0.02$ \\
\hline Road distance (m) & 0.002 & 0.001 & 9.159 & 0.003 & & & & \\
\hline Vegetation height (cm) & -0.190 & 0.033 & 32.665 & $<0.001$ & & & & \\
\hline Legume cover $(\%)$ & 0.053 & 0.026 & 3.947 & 0.047 & & & & \\
\hline Green herbs cover $(\%)$ & 0.044 & 0.015 & 9.074 & 0.003 & & & & \\
\hline Site & & & 1.251 & 0.535 & & & & \\
\hline Constant & 1.359 & 0.810 & & & & & & \\
\hline
\end{tabular}

Estimates $(B)$ and standard error (SE) of coefficients are shown for continuous variables only in model (c); coefficients of category levels for variables in models (a) and (b) are shown in Fig. 3. Significance, assessed by $\chi^{2}$ test of the change in -2LLR following variable removal from the minimal model, is presented for all retained variables

accuracy (93.5\% of all points correctly classified) and very good internal model fit with an AUC of $0.94 \pm 0.02 \mathrm{SE}$. Residuals of the model did not show any sign of autocorrelation. Males' probability of occurrence increased with shorter vegetation, higher legume and green herb cover and greater distance to roads (Table 4c).

\section{Discussions}

Habitat preference by male little bustard at landscape and local scales

This study confirms and supports the importance of pasture and recent fallows in the landscape for displaying male little bustards (Wolff et al. 2002). It also confirms the importance of small-scale habitat requirements for the species, such as cover of legumes and green herbs (Jiguet et al. 2002; Morales et al. 2008), short vegetation structure (Martinez 1994) and distance from roads, and finally highlights the fundamental role of grazing livestock in maintaining suitable habitat structure for the species in agro-pastoral steppe-like landscapes.

Our results demonstrate the crucial importance of traditional farming systems which include adequate cover of pastures and recent fallows for the little bustard. These land-uses, associated with low-intensity agro-pastoral activities, are rapidly disappearing from most of the Palaearctic but still occur locally in southern Mediterranean regions and are well known as a suitable habitat for the little bustard in Iberia (Martinez 1994; Salamolard and Moreau 1999; Suarez-Seoane et al. 2002) and southern France (Wolff et al. 2001). A strong preference for high heterogeneity of land-use substrates was also evident in the non-spatial model but not in that incorporating spatial autocorrelation. These contrasting results suggest that the clustering of displaying males in areas of high land-use heterogeneity may be related to ecological requirements of the species, as found in other areas (Martinez 1994; Wolff et al. 2002), but may be overlooked if the spatial correlation resulting from the conspecific attraction of breeding males is accounted for.

Contrary to other studies (Suarez-Seoane et al. 2002; Silva et al. 2004; Osborne and Suarez-Seoane 2007; Silva et al. 2010), we found no effect of proximity to anthropogenic infrastructures on the occurrence of little bustards at the landscape scale. However, at the smaller scale, displaying males located at points further from roads, suggesting that when not constrained by the availability of pastures and new fallows, roads were avoided. At this local scale, 
Fig. 3 Estimated coefficients $( \pm \mathrm{SE})$ of (a) land-use type from the spatial model, (b) land-use and (c) heterogeneity variables in logistic non-spatial model of little bustard incidence at the landscape scale. The reference class set in the logistic models (other land-use in panel a and $\mathrm{b}$, high heterogeneity class in panel c) are also shown by black thick lines along the vertical $(x=0)$ axis
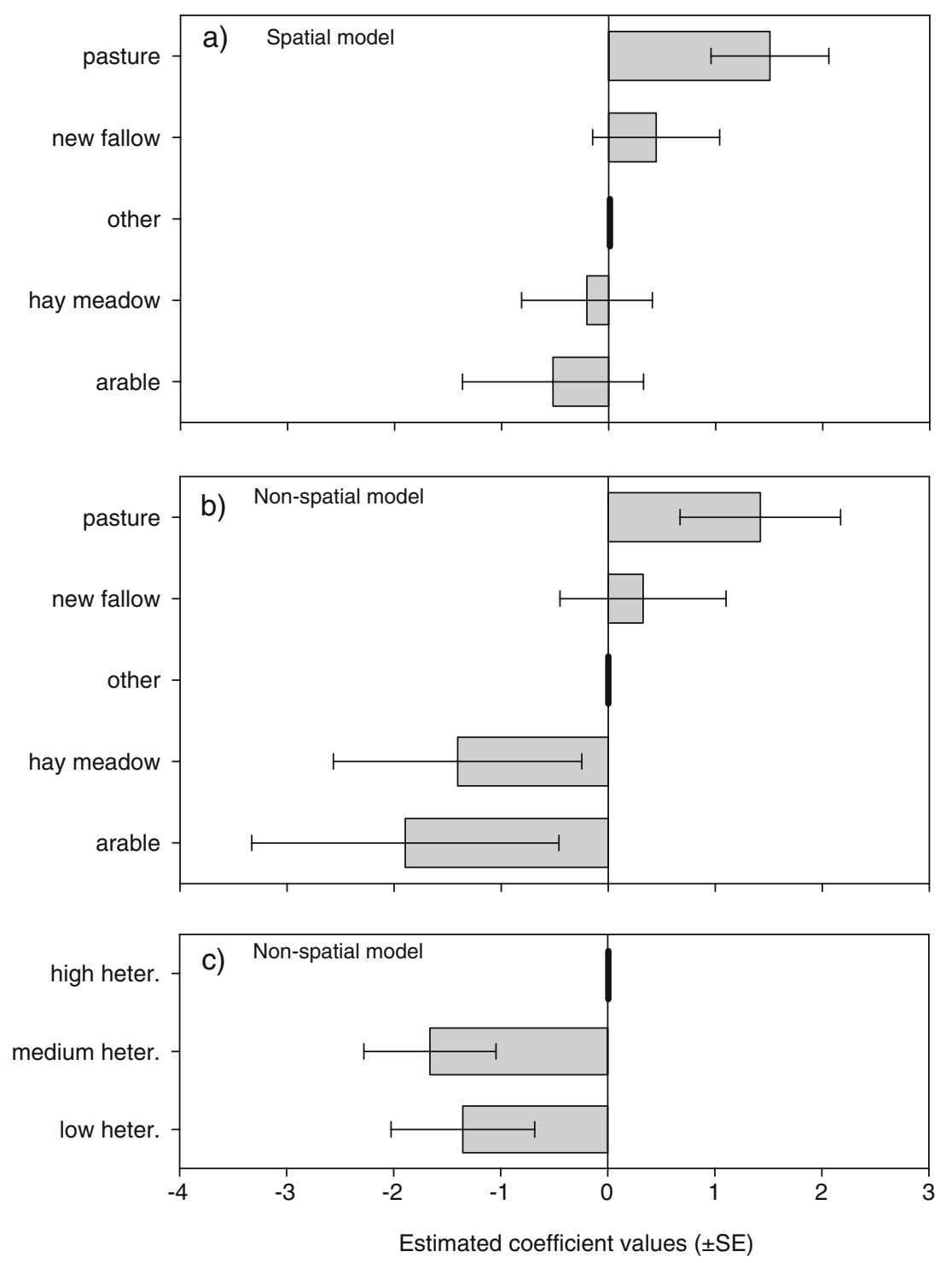

bustards also selected areas with higher content of legumes and green herbs and shorter sward height that may relate to food requirements and adequate visibility for displaying males (Martinez 1994; Salamolard and Moreau 1999; Wolff 2005). That such clear and strong associations with landuse, vegetation structure and quality were apparent suggests either that the distribution of little bustard is not constrained by lek inertia at these scales or that patterns of local and landscape suitability are stable at timescales relevant to the longevity of individuals and territories.

The importance of high grazing intensity in maintaining low vegetation structure suitable for displaying males emphasises the need to preserve sheep rearing activities in our agropastoral landscapes and elsewhere. The extent of pasture areas in Sardinia has rapidly decreased in recent decades (Falcucci et al. 2007), and if this continues, suitable areas for the species may become increasingly scarce and isolated.
Differences in little bustard density, land-use composition and structure among the contrasting landscapes

The differences in densities observed between the three sites in Sardinia can be largely explained in terms of differences in the availability of suitable land-use types, such as pasture and new fallow, and disturbance patterns.

As predicted, the highest male density occurred at $A B$ which is the least impacted by road disturbance and provides a balance of cropland and pasture cover that has previously been found to represent an optimal combination for little bustard (Martinez 1994; Wolff et al. 2002).

Again in agreement with predictions, lower density was found at $\mathrm{CO}$ that is likely the result of the scarcity of pasture and dominance of cereal fields in addition to the higher road disturbance compared to AB. However, the low density at CA that had a broadly similar balance of 
cropland and pasture to $\mathrm{AB}$ may at least partly relate to the taller, and thus less suitable, vegetation within pastures and recent fallows, as well as higher road disturbance. In the case of CA, other factors than those included in this study may have been responsible for the low numbers recorded. One possible explanation may be due to the social organisation of the species where displaying males attract each other (Jiguet et al. 2000) so that larger leks may be more attractive than smaller ones; thus, in Campeda the small population may be less attractive to settling males, despite suitable habitat being available in the area.

Implications for management and conservation of little bustards in agro-pastoral landscapes

Livestock rearing in pasturelands interspersed by extensively cultivated areas is known to support an important community of birds and other taxa in agro-pastoral landscapes (Lemaire et al. 2005). In most parts of Europe, large areas once used for mixed farming are now subject to a rapid intensification of both cropping and dairy practices that has led to local and even regional specialisation with the most fertile soils used for cereal cropping and less fertile areas devoted to intensive animal production (Lemaire et al. 2005). This has led to the disappearance of grasslands from most cereal production regions of North-western Europe and associated biodiversity losses (Robinson and Sutherland 2002). For little bustard, the disappearance of pastures and fallow lands across Europe has been identified as the major driver of national extinctions and population declines across its Palaeartic range (Del Hoyo et al. 1996; De Juana 2009). The clear preference for pasture and recent fallows in Sardinia and the clear importance of grazing livestock in maintaining short vegetation for displaying males indicate that traditional agro-pastoral activities should be preserved in order to prevent further losses of little bustard populations. Such measures will also benefit the wider assemblage of species of conservation concern, such as stone curlew Burhinus oedicnemus, calandra lark Melanocorypha calandra and griffon vulture Gyps fulvus, that depend on traditional low-intensity land-use and that are currently under pressure from agricultural intensification (Tucker 1997).

As human demands for rural development are consistently increasing, the role of agri-environmental schemes may prove fundamental to enhance the conservation of low density farmland species that require strategic intervention at the landscape scale. However, the recent abolition of obligatory set aside within the European Union may exacerbate declines in grasslands within the agro-pastoral mosaic that is likely to increase the pressure on the already imperilled species associated with traditional farming ecosystems.
Acknowledgements We would like to thank Nigel Collar for encouragement throughout this study and the Agriturismo Nurag'elighe for logistic support. We are grateful to Mauro Aresu and Andreina Concas for their valuable assistance in field work, Alberto Cardillo for the assistance with spatial analysis and to all the landowners who kindly granted us access to their land. A. Santangeli was supported by a grant from the Sir Philip Reckitt Educational Trust. Two anonymous referees are also acknowledged for their constructive comments that improved the paper.

\section{References}

Buckland ST, Anderson DR, Burnham KP, Laake JL, Borchers DL, Thomas L (2001) Introduction to distance sampling: estimating abundance of biological populations. Oxford University Press, Oxford

Chamberlain DE, Fuller RJ, Bunce RGH, Duckworth JC, Shrubb M (2000) Changes in the abundance of farmland birds in relation to the timing of agricultural intensification in England and Wales. J Appl Ecol 37:771-788

Cramp S, Simmons K (1980) The birds of the Western Palearctic hawks to bustards. Oxford University Press, Oxford

De Juana E (2009) The dramatic decline of the little bustard Tetrax tetrax in Extremadura (Spain). Ardeola 56:119-125

De Juana E, Martinez C (1996) Distribution and conservation status of the little bustard Tetrax tetrax in the Iberian Peninsula. Ardeola 43:157-167

De Juana E, Martinez C (2001) Little bustard (Tetrax tetrax). In: Schaffer N, Gallo-Orsi U (eds) European Union Action Plans for eight priority bird species. European Commission, Luxembourg, pp 1-17

Del Hoyo J, Elliot A, Sargatal J (1996) Handbook of the birds of the world, vol 3. Lynx Editions, Barcelona

Donald PF, Green RE, Heath MF (2001) Agricultural intensification and the collapse of Europe's farmland bird populations. Proc R Soc B 268:25-29

Donald PF, Sanderson FJ, Burfield IJ, van Bommel FPJ (2006) Further evidence of continent-wide impacts of agricultural intensification on European farmland birds, 1990-2000. Agric Ecosyst Environ 116:189-196

Dormann CF et al (2007) Methods to account for spatial autocorrelation in the analysis of species distributional data: a review. Ecography 30:609-628

Falcucci A, Maiorano L, Boitani L (2007) Changes in land-use/landcover patterns in Italy and their implications for biodiversity conservation. Landsc Ecol 22:617-631

Faria N, Rabaca JE (2004) Breeding habitat modelling of the little bustard Tetrax tetrax in the site of community importance of Cabrela (Portugal). Ardeola 51:331-343

Freckleton RP (2002) On the misuse of residuals in ecology: regression of residuals vs. multiple regression. J Anim Ecol 71:542-545

García de la Morena EL, Bota G, Ponjoan A, Morales MB (2006) El sisón común en España. I Censo Nacional (2005). Sociedad Española de Ornitología/BirdLife, Madrid

Goriup P (1994) Little Bustard Tetrax tetrax. In: Birdlife International (ed) Birds in Europe: their Conservation Status. Tucker, G.M. Heath, M.F., Cambridge, pp 236-237

Hosmer DW, Lemeshow S (2000) Applied logistic regression. Wiley, New York

Jiguet F, Arroyo B, Bretagnolle V (2000) Lek mating systems: a case study in the little bustard Tetrax tetrax. Behav Processes 51:63-82

Jiguet F, Jaulin S, Arroyo B (2002) Resource defence on exploded leks: do male Little Bustards, Tetrax tetrax, control resources for females? Anim Behav 63:899-905 
Jolivet C (2001) L'outarde canepetière Tetrax tetrax en France. Statut del l'espèce à la fin du XX siécle. Ornithos 8:89-95

Lane SJ, Alonso JC, Martin CA (2001) Habitat preferences of great bustard Otis tarda flocks in the arable steppes of central Spain: are potentially suitable areas unoccupied? J Appl Ecol 38:193-203

Lemaire G, Wilkins R, Hodgson J (2005) Challenges for grassland science: managing research priorities. Agric Ecosyst Environ 108:99-108

Martinez C (1994) Habitat selection by the little bustard Tetrax tetrax in cultivated areas of central Spain. Biol Conserv 67:125-128

Morales MB, Traba J, Carriles E, Delgado MP, de la Morena ELG (2008) Sexual differences in microhabitat selection of breeding little bustards Tetrax tetrax: ecological segregation based on vegetation structure. Acta Oecol 34:345-353

Osborne PE, Suarez-Seoane S (2007) Identifying core areas in a species' range using temporal suitability analysis: an example using little bustards Tetrax tetrax L. in Spain. Biodivers Conserv 16:3505-3518

Petretti F (1993) Notes on the lek behaviour of the little bustard in Italy. Avocetta 17:19-22

Petretti F (2006) Conservation of steppe birdlife in Italy. In: Gafta D, Akeroyd J (eds) Nature conservation, concepts and practice. Springer, Berlin, pp 235-239

Rivas-Martinez S (1996) Clasificacion bioclimatica de la tierra. Folia Botanica Madritensis 16:1-32

Robinson RA, Sutherland WJ (2002) Post-war changes in arable farming and biodiversity in Great Britain. J Appl Ecol 39:157-176

Salamolard M, Moreau C (1999) Habitat selection by little bustard Tetrax tetrax in a cultivated area of France. Bird Study 46:25-33

Schenk H, Aresu M (1985) On the distribution, number and conservation of the little bustard in Sardinia (Italy). Bustard Stud 2:161-164

Silva JP, Faria N, Catry T (2007) Summer habitat selection and abundance of the threatened little bustard in Iberian agricultural landscapes. Biol Conserv 139:186-194

Silva JP, Pinto M, Palmeirim JM (2004) Managing landscapes for the little bustard Tetrax tetrax: lessons from the study of winter habitat selection. Biol Conserv 117:521-528

Silva JP et al (2010) Estimating the influence of overhead transmission power lines and landscape context on the density of little bustard Tetrax tetrax breeding populations. Ecol Modell 221:1954-1963
Suarez-Seoane S, Osborne PE, Alonso JC (2002) Large-scale habitat selection by agricultural steppe birds in Spain: identifying species-habitat responses using generalized additive models. J Appl Ecol 39:755-771

Suarez F, Naveso MA, De Juana E (1997) Farming in the drylands of Spain: bird of pseudosteppes. In: Pain DJ, Pienkowski MW (eds) Farming and birds in Europe. The common agricultural policy and its implications for bird conservation. Academic Press, London

Thomas L et al (2005) Distance 5.0 Beta 5. In: Research Unit for Wildlife Population Assessment. University of St. Andrews, United Kingdom

Traba J, Morales MB, de la Morena ELG, Delgado MP, Kristin A (2008) Selection of breeding territory by little bustard (Tetrax tetrax) males in central Spain: the role of arthropod availability. Ecol Res 23:615-622

Tucker GM (1997) Priorities for bird conservation in Europe: the importance of the farmed landscape. In: Pienkowski DPMW (ed) Farming and birds in Europe: the common agricultural policy and its implications for bird conservation. Academic Press, San Diego, CA, pp 79-116

Tucker GM, Evans MI (1997) Habitats for birds in Europe: a conservation strategy for the wider environment. Cambridge, UK: BirdLife International (BirdLife Conservation series no. 6)

Tucker GM, Heath MF (1994) Birds in Europe: their conservation status. Birdlife International, Cambridge

Vergara PM, Armesto JJ (2009) Responses of Chilean forest birds to anthropogenic habitat fragmentation across spatial scales. Landscape Ecol 24:25-38

Wolff A (2005) Influence of landscape and habitat heterogeneity on the distribution of steppe-land birds in the Crau, southern France. In: Bota G, Morales MB, Mañosa S, Camprodon J (eds) Ecology and Conservation of Steppe-land Birds. Lynx Edicions and Centre Tecnològic Forestal de Catalunya, Barcelona, pp 141-168

Wolff A, Dieuleveut T, Martin JL, Bretagnolle V (2002) Landscape context and little bustard abundance in a fragmented steppe: implications for reserve management in mosaic landscapes. Biol Conserv 107:211-220

Wolff A, Paul JP, Martin JL, Bretagnolle V (2001) The benefits of extensive agriculture to birds: the case of the little bustard. J Appl Ecol 38:963-975 